\title{
Factors associated with the development of dental defects acquired in the extrauterine environment
}

\section{Judith Rafaelle Oliveira PINHO(a) \\ Erika Barbara Abreu Fonseca \\ THOMAZ(a) \\ Cecília Cláudia Costa RIBEIRO(b) Cláudia Maria Coelho ALVES(b)}

Antônio Augusto Moura da SILVA(a)

(a) Universidade Federal do Maranhão - UFMA, Public Health Department, Pos-Graduate Program in Public Health, São Luís, Maranhão, Brazil.

(b) Universidade Federal do Maranhão - UFMA, Department of Dentistry II, Pos-Graduate Program in Public Health, São Luís, Maranhão, Brazil.

Declaration of Interests: The authors certify that they have no commercial or associative interest that represents a conflict of interest in connection with the manuscript.

\section{Corresponding Author:}

Judith Pinho

E-mail: judrafa@gmail.com

htrps://doi.org/10.1590/1807-3107bor-2019.vol33.0094

Submitted: August 21, 2018

Accepted for publication: May 14, 2019

Last revision: September 4, 2019
Abstract: This study aimed to analyze the association of sociodemographic, child health, healthcare service, and access indicators with developmental defects of enamel (DDE) acquired outside the uterus, based on gestational factors. A cohort of births was carried out, and 982 children aged 12 to 30 months were examined. A total of 1,500 women were followed up as of the $5^{\text {th }}$ month of gestation, and the child's gestational age was evaluated at follow-up. The clinical examination was performed as recommended by the World Health Organization, and defects were classified using the modified DDE index. Six models were considered: presence of DDE (Model 1) or opacities (Model 4), number of teeth with DDE (Model 2) or opacities (Model 5), and incidence rate of DDE (Model 3) or opacities (Model 6). Associations were estimated by relative risk (RR) in Poisson regression models. In the adjusted analysis, the mother's lowest education level was associated with the highest occurrence of DDE in Models $1(R R=26.43 ; p=0.002)$, $2(R R=9.70 ; p=0.009)$, and $3(R R=5.63 ; p=0.047)$. Breastfeeding for over 12 months $(R R=0.45 ; p=0.030)$ and recent use of anti-infection drugs $(R R=0.20 ; p=0.039)$ had a protective effect on DDE (Model 1). The factors associated with the highest incidence of opacities were not having health insurance $(R R=2.00 ; p=0.043)$ (Model 5), and belonging to a family of poor social class $(R R=4.67 ; p=0.007$ ) (Model 6). Children in a situation of socioeconomic vulnerability have a higher risk of presenting extrauterine DDE. Breastfeeding was a protection factor for DDE development.

Keywords: Dental Enamel Hypoplasia; Child Nutrition Disorders; Interpersonal Relations.

\section{Introduction}

Doubts remain regarding the etiological factors causing developmental defects of enamel (DDE). ${ }^{1}$ The origin of DDE has been attributed to environmental or genetic, and local or systemic factors. ${ }^{2}$ Its clinical presentation may vary according to the stage of development of the affected teeth, and the duration and intensity of the aggressive agents. ${ }^{3}$

There is evidence that DDE acquired after the birth of the child may occur due to periapical infections or dentoalveolar traumatism. ${ }^{4}$ Local traumatic forces resulting from the use of laryngoscopy and orotracheal 
cannula, which are frequently indicated for pretermborn (PTB) or low weight-born (LWB) children, have also been implicated in the occurrence of DDE. ${ }^{5}$ Systemic events, such as affections ${ }^{2}$ and use of medicaments ${ }^{6}$ during tooth development, have also been pointed out as potential risk factors for the occurrence of DDE, but the findings are not consistent. The occurrence of a severe disease after birth (during 0-3 years of age) can be associated with an almost eightfold higher DDE rate than that of healthy children. ${ }^{1}$

There is also evidence that nutritional status might affect tooth formation before and after its eruption. In 1993, an extensive systematic review of the literature indicated that vitamin $\mathrm{D}$ and calcium deficiencies are directly related to the increase in DDE. ${ }^{7}$ The study found that vitamin $\mathrm{D}$ and calcium supplementation in the pre-eruptive period can reduce the incidence of caries, possibly due to a reduction in DDE incidence. The intake of vitamins $\mathrm{A}$ and $\mathrm{C}$ was also related to DDE. ${ }^{8}$ Thus, nutritional status might be related to enamel defects. The chance of a malnourished child presenting DDE may be 3.7 higher than that of a eutrophic child. ${ }^{9}$ The authors of this study included breastfeeding as an essential factor in defining adequate nutritional status.

Adequate nourishment plays an important role in determining oral health. As of the first hours of an infant's life, breastfeeding by the mother is of foremost importance, because it supplies children with all needed nutrients, ${ }^{10}$ including the vitamins and minerals essential to tooth formation., ${ }^{911}$ However, studies do not differentiate between extrauterine defects and those acquired during the gestational period, thereby biasing the association estimates. A systematic review indicates that postnatal conditions will cause defects in enamel parts formed after birth. ${ }^{12}$ Furthermore, most of the available etiological studies identified are subject to biased measurements due to the retrospective collection of data, thus making results controversial. One recent systematic review pointed out that the internal and external validity of the investigations on this topic must be improved ${ }^{6}$. Little evidence has been produced from longitudinal studies that have a probabilistic sample and are large in size. ${ }^{13}$

This study aimed to analyze the association among sociodemographic, child health, and healthcare service and access indicators, on one hand, and DDE acquired outside the uterus and related to gestational factors, on the other hand. The present investigation tests the hypothesis that sociodemographic and child health factors, along with healthcare service and access indicators, are related to extrauterine DDE.

\section{Methodology}

A prospective, population-based cohort of births was carried out. The study was part of a project entitled, "Etiological factors of preterm birth and consequences of perinatal factors on children's health: birth cohorts from two Brazilian cities (BRISA)." It was developed by the Federal University of Maranhão (UFMA) in a partnership with the University of São Paulo (USP), Ribeirão Preto campus. This research was approved by the Research Ethics Committee (223/2009).

Epi Info software version 7.0 was used to estimate an initial sample of 916 children to perform population inferences with $95 \%$ confidence, considering the frequency of the disease to be $16 \%,{ }^{13}$ a sample error of $4 \%$ in bilateral tests, and a design effect of 2.0. This sample size would still have a power of $80 \%$ to identify relative risks of up to $1.7 \%$, with a ratio of $1: 1$ between exposed and non-exposed individuals.

This cohort included $1 / 3$ of the children born alive in hospitals, non-twins, children of women who lived in the municipality of São Luís, northeastern Brazil, in the year of 2010, totaling 5,067 children. Some of the children were contacted and invited to return to the study site for clinical assessment in their second year of life. These included all the children with PTB and/or LWB, and a sample of those born at full-term, obtained by simple random sampling, in a proportion of three births at full-term to every child with PTB (<36 weeks ) / LWB $(<2.500 \mathrm{~g}){ }^{14} \mathrm{~A}$ total of 982 children aged 12 to 30 months were examined from July 2011 to February 2013. 
Each child was examined in a portable dental chair, under artificial light, after tooth drying by air jets, using a WHO-621 periodontal probe and a mouth mirror (@2013 Hu-Friedy), sterilized previously and packaged individually. Five trained examiners conducted the procedure to diagnose DDE (Kappa inter-examiner > 8.0). The calibration of the examiners was performed by examining 20 children in the pediatric dentistry clinic of the Federal University of Maranhão. Diagnosis of the dental enamel defects was performed according to a modified version of the Developmental Defects of Enamel (DDE) Index proposed by the World Dental Federation. ${ }^{15}$

The examination considered that the process of tooth development occurs at different moments. ${ }^{16}$ Accordingly, the tooth was measured with a WHO-621 periodontal probe, so that the position of the defect could be measured and classified, according to formation chronology, based on the location, DDE type, and tooth group. Once the DDE was identified, the tooth was classified according to opacity, hypoplasia, and other defects, as well as the location of the intrauterine (DDE-IU) or extrauterine defect (DDE-EU). Only DDE-EU was considered in the present investigation.

The covariables of the study were organized into three blocks, according to a hierarchized theoretical model (Figure 1). The arrangement of the variables in this theoretical model was explained by the following hypothesis: a) opacities and hypoplasia would be affected differently by postnatal factors; b) social and demographic conditions could determine the presence of DDE and opacities, and also the number of teeth affected by these conditions; and c) socioeconomic conditions, such as health conditions, ${ }^{6,12}$ use of medicaments, ${ }^{6}$ and breastfeeding ${ }^{2,19,20}$ might influence the appearance of enamel defects..$^{12,17,18}$.

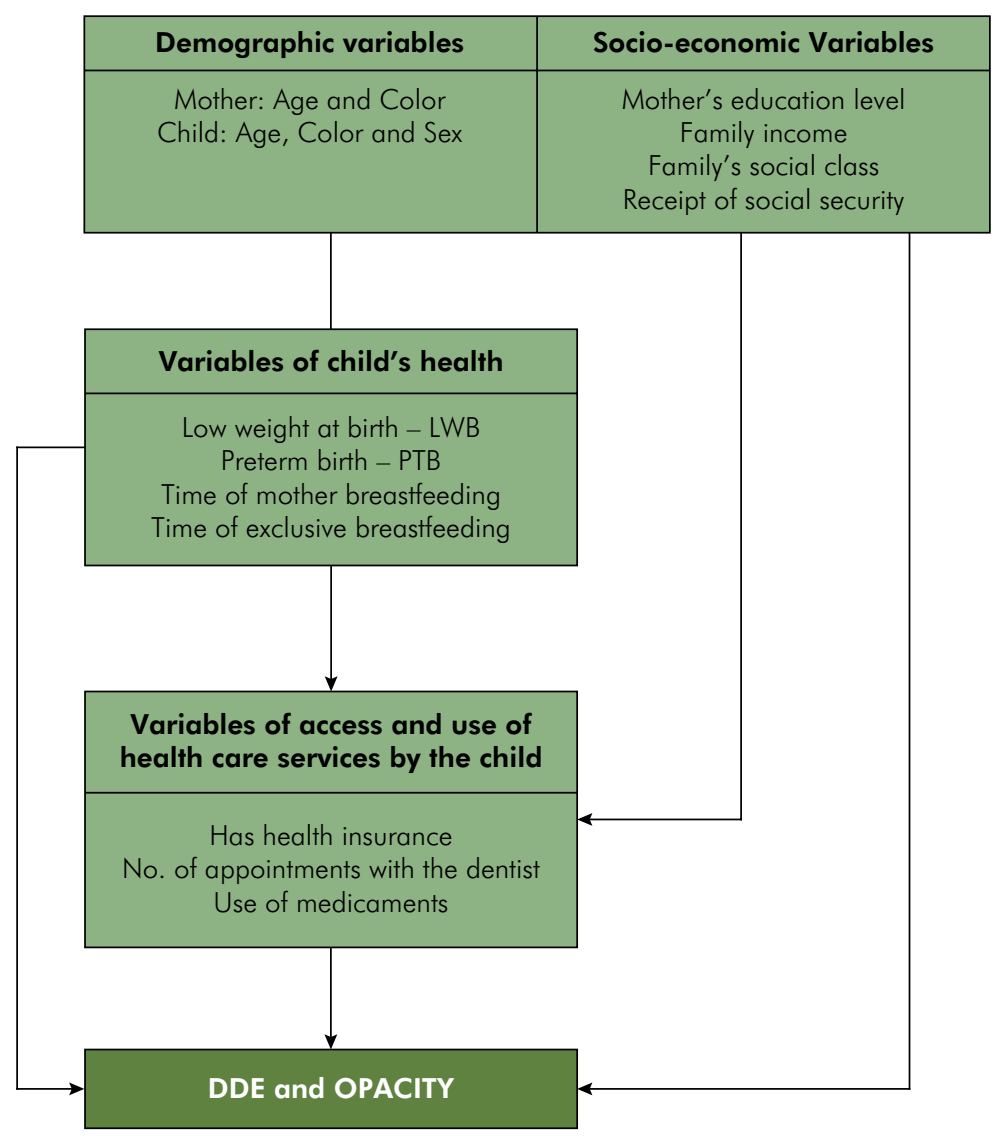

Figure 1. Theoretical model explaining the factors associated with DDE of extra-uterine origin. 
Opacities were adopted as an outcome due to the chronology of dental enamel formation, ${ }^{21,22}$ considering that, in the period of extrauterine formation, the mineralization phase would be the period most vulnerable to interferences. Table 1 presents the theoretical model of the variables associated with DDE and opacities. The model was hierarchized on three levels. At the most distal level, there are two blocks of variables: demographic and socioeconomic (categorized according to ABEP criteria). ${ }^{23}$ The child health variables are at the intermediate level, and the variables of access to and use of healthcare services by the child are in the proximal block. All the variables influenced the outcome, directly and indirectly, mediated by the variables of the subsequent levels. Accordingly, the theoretical model allowed estimation of the association among variables adjusted by the variables of the previous levels.

The type of medicament used during pregnancy was classified according to the Anatomical Therapeutic Chemical (ATC) Classification System, ${ }^{24}$ which classifies the medicaments into 14 categories. The present investigation highlighted the medicaments potentially capable of influencing the formation of dental enamel, whether positively or negatively. Accordingly, the use of medicaments was re-categorized into the following categories: any medicament used; alimentary tract and metabolism (vitamins, antacids, antiemetic and antihyperglycemic drugs, medicaments for gastrointestinal disorders); blood components (antianemia, antithrombotic and antihemorrhagic drugs); and anti-infection drugs (antibiotics, antifungal and antiparasitic drugs, and others).

The data were analyzed by Stata software, version 12.0 (Stata, College Station, USA), and six different models were studied, according to the outcome under study: Model 1: outcome - extrauterine DDE, dichotomized into yes or no; Model 2: outcome number of teeth with extrauterine DDE; Model 3: outcome - incidence rate of extrauterine DDE; Model 4: outcome - dental opacity of extrauterine origin, dichotomized into yes or no; Model 5: outcome number of teeth with extrauterine opacity; Model 6: outcome - incidence rate of opacities. DDE and opacity incidence rates were calculated by dividing the number of teeth with DDE and opacity, respectively, by the total number of teeth erupted up to the time of the exam. A descriptive statistical analysis was also carried out.

The process of development of the tooth enamel occurs, on average, at up to three years of age, in three stages: a) ameloblast secretion (a stage directly influenced by adequate levels of vitamin A, C, and D); b) mineralization; and c) maturing (directly affected by levels of calcium and phosphorus). ${ }^{21}$ If an alteration occurs in the enamel matrix deposition stage, it will result in hypoplastic malformations, and if it occurs in the enamel maturation phase, it will result in hypomineralization..$^{22}$ The analysis of different models was chosen considering all the DDEs and specifically the opacities (hypoplasia and hypomineralization).

Table 1. Description of the variables of the hierarchized model.

\begin{tabular}{|c|c|}
\hline Block & Variables \\
\hline $\begin{array}{l}\text { Socio-demographic variables of the } \\
\text { mother/family and child }\end{array}$ & $\begin{array}{c}\text { Mother/family: age of the mother (adult or adolescent) self-defined skin color of the mother } \\
\text { (white or non-white), education level of the mother ( } \geq 12 \text { years, } 9-11 \text { years or } \leq 8 \text { years), family } \\
\text { income ( }>2 \text { minimum wages }-\mathrm{MW},-1-2 \mathrm{MW} \text { or }<1 \mathrm{MW} \text { ), social class of the family (categorized } \\
\text { according to ABEP23 in } A / B, C \text { or } D / E) \text {, access to social security Bolsa Família (yes or no); child: age } \\
\text { (categorized according to the median in up to } 16.6 \text { months or }>16,6 \text { months), sex (male or female), } \\
\text { color of the child defined by the mother (white or non-white). }\end{array}$ \\
\hline Variables of child's health & $\begin{array}{c}\text { Low weight at birth - LWB, defined as less than } 2,500 \mathrm{~g} \text { and preterm birth }- \text { PTB, defined as the birth } \\
\text { with less than } 37 \text { weeks of pregnancy (categorized in neither one, only LWB, only PTB, or LWB and } \\
\text { PTB), breastfeeding time ( }>12 \text { months, } 6 \text { to } 12 \text { months or }<6 \text { months) and exclusive breastfeeding } \\
\text { up to } 6 \text { months (yes or no). }\end{array}$ \\
\hline $\begin{array}{l}\text { Variables of access and use of health } \\
\text { care services }\end{array}$ & $\begin{array}{l}\text { Has health insurance (yes or no), has already been seen by the dentist (yes or no), use of } \\
\text { medicaments in the last two weeks (any, medicament of alimentary tract, hemocomponents, anti- } \\
\text { infection medicament, or others) }\end{array}$ \\
\hline
\end{tabular}


The ameloblast secretion stage of deciduous teeth occurs, especially in intrauterine life. Thus, at the age of the children examined in the study (12-30 months), erupted teeth would have already undergone the ameloblast secretion stage and would be in the process of mineralization and maturing. This explains why a separate analysis of opacities is needed.

The associations were estimated by relative risk (RR) and respective confidence intervals at 95\% (95\% CI) with Poisson regression models. These models are good alternatives for obtaining adequate RR estimates, even in studies where the outcome of the enamel development defect is frequent. The hierarchized approach was adopted for modeling, according to the theoretical model proposed in Table 1. All of the analyses were considered in the inverse probability of the child segment, using "SVY" commands. Children with LWB and/or PTB had a lower rate of segment loss. On the other hand, the losses were higher in children whose mothers belonged to either extreme of the education and the family income ranges. Therefore, we considered these variables in the assessment.

\section{Results}

The incidence of extrauterine DDE in the sample was $8.81 \%$ in children between 12 and 30 months. The opacities were the most frequent defects found (Table 2). The number of children with extrauterine DDE by dental group is shown in Table 3.

In the non-adjusted analysis, the lowest level of maternal education and no health insurance were associated with the highest occurrence of DDE. The following variables were associated with the lowest occurrence of DDE in the child: not receiving "Bolsa Família" (a Brazilian social assistance program), and longest breastfeeding time. The variables associated with the highest occurrence of opacities were the following: belonging to low social classes; low level of maternal education; low family income; and no health insurance. On the other hand, the following factors were associated with the lowest occurrence of opacities: not receiving "Bolsa Família"; longest breastfeeding time; and use of anti-infection medicaments (Table 4).
In the adjusted analysis, the lowest level of maternal education was associated with the highest occurrence of DDE in Models 1 ( $R R=26.43 ; p=0.002), 2(R R=9.70$; $p=0.009)$, and $3(R R=5.63 ; p=0.047)$. The recent use of blood components $(R R=6.37 ; p=0.025)$ was associated with the highest incidence of DDE (Model 2). Being breastfed for over 12 months $(R R=0.45 ; p=0.030)$ and recent use of anti-infection medicaments $(R R=0.20$; $p=0.039)$ had a protective effect on the presence of DDE (Model 1). The factors associated with the highest incidence of opacities were the following: not having health insurance $(R R=2.00 ; p=0.043)($ Model 5$)$ and belonging to a family of low social class $(\mathrm{RR}=4.67$; $p=0.007$ ) (Model 6). The following factors were associated with the lowest incidence of opacities: having been breastfed for over 12 months, in Models 4 $(\mathrm{RR}=0.37 ; \mathrm{p}=0.021)$ and $6(\mathrm{RR}=0.07) ; \mathrm{p}=0.004)$; not having been treated by a dentist $(R R=0.29 ; p=0.030)$ (Model 6); and having recently used anti-infection medicaments, in Model $5(\mathrm{RR}=0.24 ; \mathrm{p}=0.046)$ and 6 $(R R=0.12 ; p=0.014)$. The use of vitamin and minerals supplements since birth was not associated with the occurrence of enamel defects (Table 5).

\section{Discussion}

This study had a population-based prospective design. It pioneered in the investigation of the factors associated with extrauterine enamel defects detected at a certain site. The results indicate that children who have a higher risk of presenting DDE, including opacities, are those from a less-favored social class - not consistent with the results found in the literature-those whose mothers have less education, those who do not have health insurance, and those whose mothers reported use of blood components, especially, iron. On the other hand, a long breastfeeding time (> 12 months) and the use of a few medicaments-especially anti-infection drugs-were protective factors for the development of these defects.

Some studies have reported the influence of socioeconomic conditions on $\mathrm{DDE}^{17,18}$. A study conducted in Brazil ${ }^{20}$ indicated that income $(<2$ minimum wages; $\mathrm{p}=0.030)$ and mother's age ( $>24$ years; $p=0.012$ ) were risk factors for DDE. In the 
Factors associated with the development of dental defects acquired in the extrauterine environment

Table 2. Characteristics of the population of the study, according to the presence of extrauterine DDE. São Luís, Brazil. $2010-2013$.

\begin{tabular}{|c|c|c|c|c|}
\hline \multirow{3}{*}{ Variables } & \multirow{2}{*}{\multicolumn{2}{|c|}{ Total }} & \multicolumn{2}{|c|}{ DDE } \\
\hline & & & \multirow{2}{*}{$\begin{array}{c}\text { Hypoplasia } \\
4 \%\end{array}$} & \multirow{2}{*}{$\begin{array}{c}\text { Opacities } \\
4 \%\end{array}$} \\
\hline & $\mathrm{n}$ & $4 \%$ & & \\
\hline \multicolumn{5}{|c|}{ Sociodemographic variables of the mother/family } \\
\hline \multicolumn{5}{|l|}{ Mother's age } \\
\hline Adult & 787 & 79.9 & 8.9 & 21.6 \\
\hline Adolescent & 191 & 20.1 & 8.0 & 19.1 \\
\hline \multicolumn{5}{|l|}{ Mother's color } \\
\hline White & 168 & 17.59 & 9.4 & 18.9 \\
\hline Non-white & 787 & 82.41 & 8.0 & 19.9 \\
\hline \multicolumn{5}{|l|}{ Social class $(A B E P)^{1}$} \\
\hline $\mathrm{A} / \mathrm{B}$ & 158 & 16.2 & 4.9 & 16.8 \\
\hline C & 587 & 60.1 & 9.7 & 19.7 \\
\hline $\mathrm{D} / \mathrm{E}$ & 220 & 23.7 & 6.8 & 21.6 \\
\hline \multicolumn{5}{|c|}{ Mother's education (years of education) } \\
\hline$\geq 12$ & 168 & 13.8 & 2.2 & 14.3 \\
\hline 6 to 12 & 135 & 63.4 & 7.7 & 18.7 \\
\hline$\leq 8$ & 652 & 22.8 & 13.5 & 24.6 \\
\hline \multicolumn{5}{|c|}{ Family income (in minimum wages) ${ }^{2}$} \\
\hline$>2$ & 410 & 50.7 & 7.2 & 18.6 \\
\hline 1 to 2 & 319 & 40.7 & 7.8 & 18.8 \\
\hline$<1$ & 70 & 8.6 & 11.5 & 20.8 \\
\hline \multicolumn{5}{|l|}{ Receives Bolsa Família } \\
\hline Yes & 665 & 69.6 & 7.2 & 19.4 \\
\hline No & 291 & 30.4 & 8.6 & 1.9 \\
\hline \multicolumn{5}{|c|}{ Sociodemographic variable of the child } \\
\hline \multicolumn{5}{|l|}{ Age (months) ${ }^{3}$} \\
\hline Up to 16.6 & 290 & 50.4 & 7.1 & 18.2 \\
\hline$>16.6$ & 290 & 49.6 & 8.5 & 18.5 \\
\hline \multicolumn{5}{|l|}{ Color } \\
\hline White & 242 & 25.4 & 6.9 & 16.4 \\
\hline Non-white & 710 & 74.6 & 8.6 & 20.8 \\
\hline \multicolumn{5}{|l|}{ Sex } \\
\hline Male & 516 & 54.4 & 8.7 & 21.2 \\
\hline Female & 449 & 45.6 & 7.7 & 17.8 \\
\hline \multicolumn{5}{|l|}{ Child's health } \\
\hline \multicolumn{5}{|c|}{ Low weight at birth and preterm birth } \\
\hline Neither one & 652 & 68.9 & 8.1 & 19.48 \\
\hline Both & 93 & 9.9 & 8.1 & 21.51 \\
\hline Only low weight at birth & 53 & 5.6 & 5.7 & 20.75 \\
\hline Only preterm birth & 147 & 15.6 & 11.6 & 20.41 \\
\hline
\end{tabular}

Continue 


\begin{tabular}{|c|c|c|c|c|}
\hline \multicolumn{5}{|l|}{ Continuation } \\
\hline \multicolumn{5}{|c|}{ Duration of breastfeeding (months) } \\
\hline$>12$ & 700 & 76.25 & 8.07 & 20.07 \\
\hline 6 to 12 & 115 & 12.53 & 5.87 & 12.97 \\
\hline$<6$ & 103 & 11.22 & 13.88 & 24.50 \\
\hline \multicolumn{5}{|c|}{ Exclusive breastfeeding up to 6 months } \\
\hline Yes & 389 & 42.8 & 9.8 & 20.73 \\
\hline No & 562 & 57.2 & 7.0 & 18.91 \\
\hline \multicolumn{5}{|c|}{ Access to and use of healthcare services } \\
\hline \multicolumn{5}{|l|}{ Has health insurance } \\
\hline Yes & 231 & 24.16 & 5.07 & 14.23 \\
\hline No & 725 & 75.84 & 9.17 & 21.27 \\
\hline \multicolumn{5}{|c|}{ Has already had an appointment with the dentist } \\
\hline Yes & 43 & 4.50 & 10.68 & 26.19 \\
\hline No & 913 & 95.5 & 8.09 & 19.31 \\
\hline \multicolumn{5}{|l|}{ Has used medicaments } \\
\hline Any one & 473 & 49.02 & 8.98 & 20.71 \\
\hline Alimentary tract & 240 & 24.87 & 5.72 & 18.16 \\
\hline Hemo-components & 13 & 1.35 & 8.62 & 8.62 \\
\hline Anti-infection & 62 & 6.42 & 4.28 & 12.21 \\
\hline Others & 177 & 18.34 & 10.98 & 22.42 \\
\hline
\end{tabular}

Table 3. Number of children with extrauterine DDE by dental group. São Luís, Brazil.

\begin{tabular}{|c|c|c|c|c|c|c|}
\hline \multirow{2}{*}{ Dental group } & \multicolumn{3}{|c|}{ Without DDE } & \multicolumn{3}{|c|}{ Extrauterine $\mathrm{DDE}^{1}$} \\
\hline & $f$ & $\%$ & $95 \% \mathrm{Cl}$ & $f$ & $\%$ & $95 \% \mathrm{Cl}$ \\
\hline Incisors & 790 & 81.3 & $77.4-84.6$ & 39 & 4.0 & $2.5-6.4$ \\
\hline Canines & 933 & 96.0 & $93.7-97.4$ & 13 & 1.5 & $0.7-3.2$ \\
\hline Molars & 923 & 94.1 & $91.4-96.0$ & 6 & 1.1 & $0.4-3.3$ \\
\hline
\end{tabular}

present research, the data indicate that a maternal education level of fewer than eight years and a low social class were associated, respectively, to higher rates of DDE and opacity incidence.

Breastfeeding had a protective effect against extrauterine DDE, as observed in the analytical models that assessed the presence of opacities, and in the model that analyzed the presence of all DDEs. The greater the breastfeeding time, the smaller the likelihood of developing any defect. In children breastfed for up to 12 months, the risk was 0.45 for DDE and 0.37 for opacities, after adjustment. A similar result was observed for the tooth opacity rate, related to the nutritional composition of mother's milk, rich in calcium, phosphorus ${ }^{25}$, and vitamins, ${ }^{11,26}$ which are essential for enamel mineralization. Significant differences were not observed in the number of teeth affected by some kind of DDE.

Studies that analyze the effect of breastfeeding on the development of enamel defects are inconclusive. Children who are not breastfed present higher chances $(\mathrm{OR}=3.2 ; 95 \% \mathrm{CI}=1.2-8.4)$ of presenting DDE. ${ }^{2}$ A study performed in Tanzania ${ }^{19}$ found no association between the presence of opacities and breastfeeding after adjustment for socioeconomic variables, contradicting the findings of the present research. It is also important 


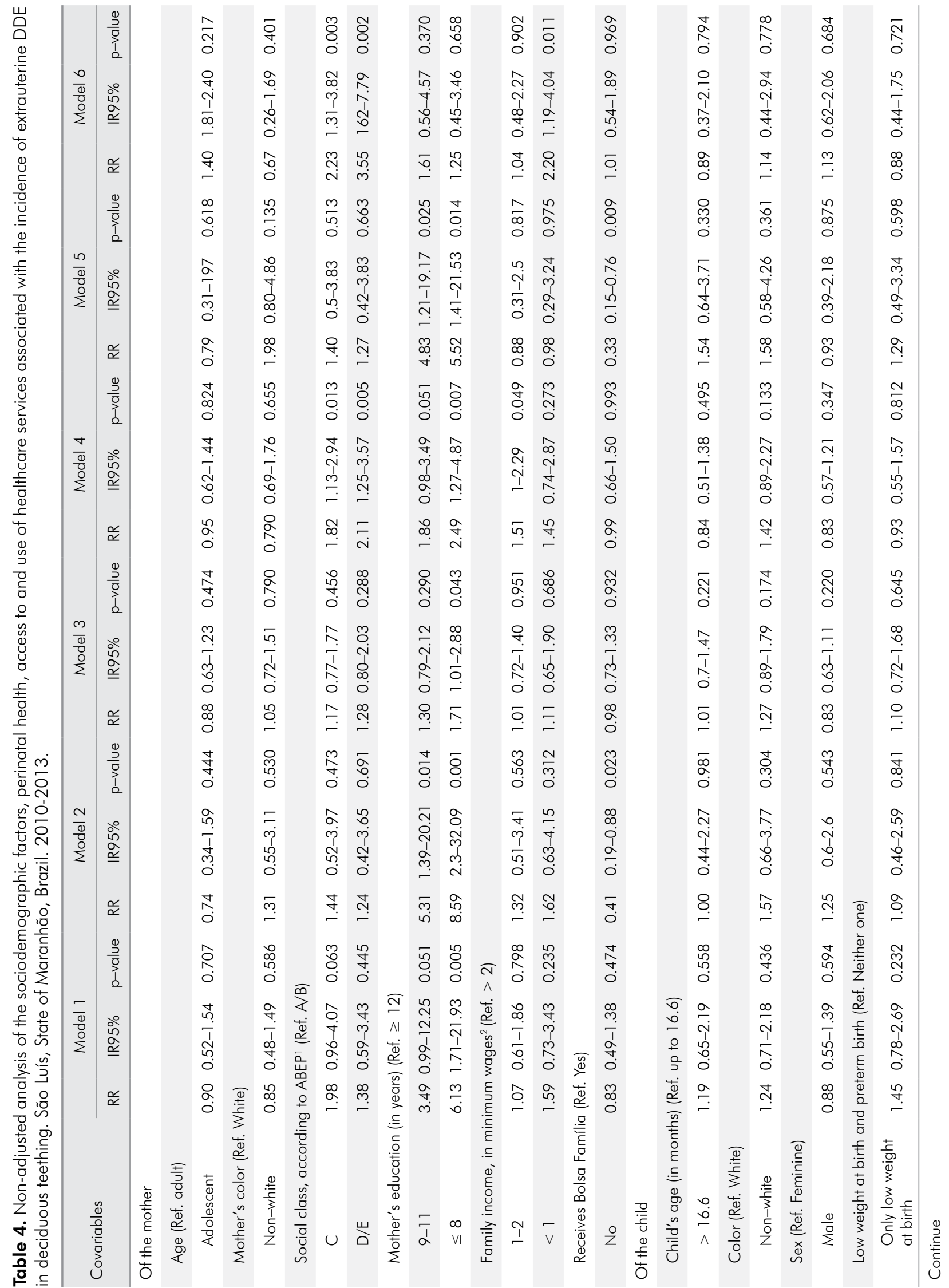




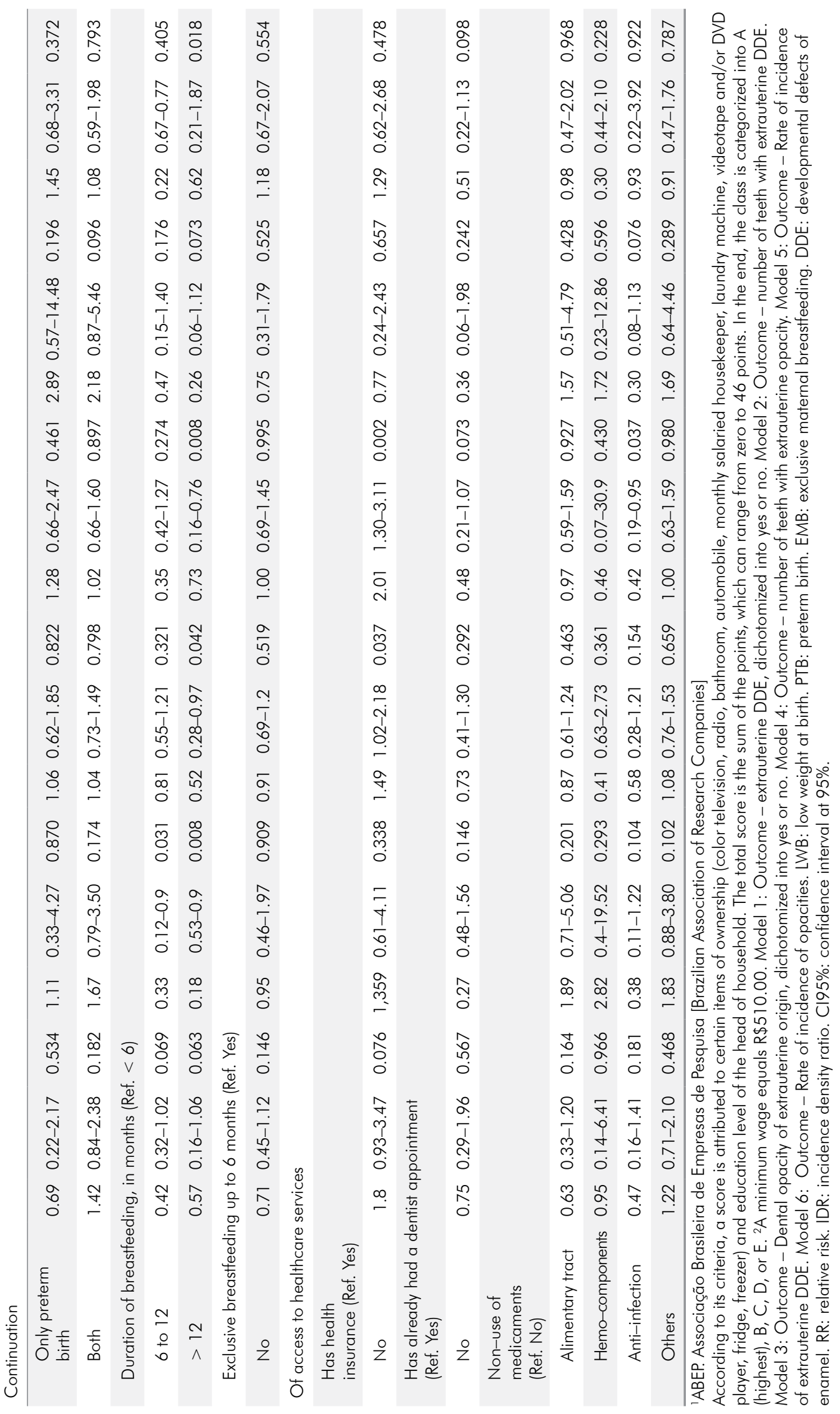




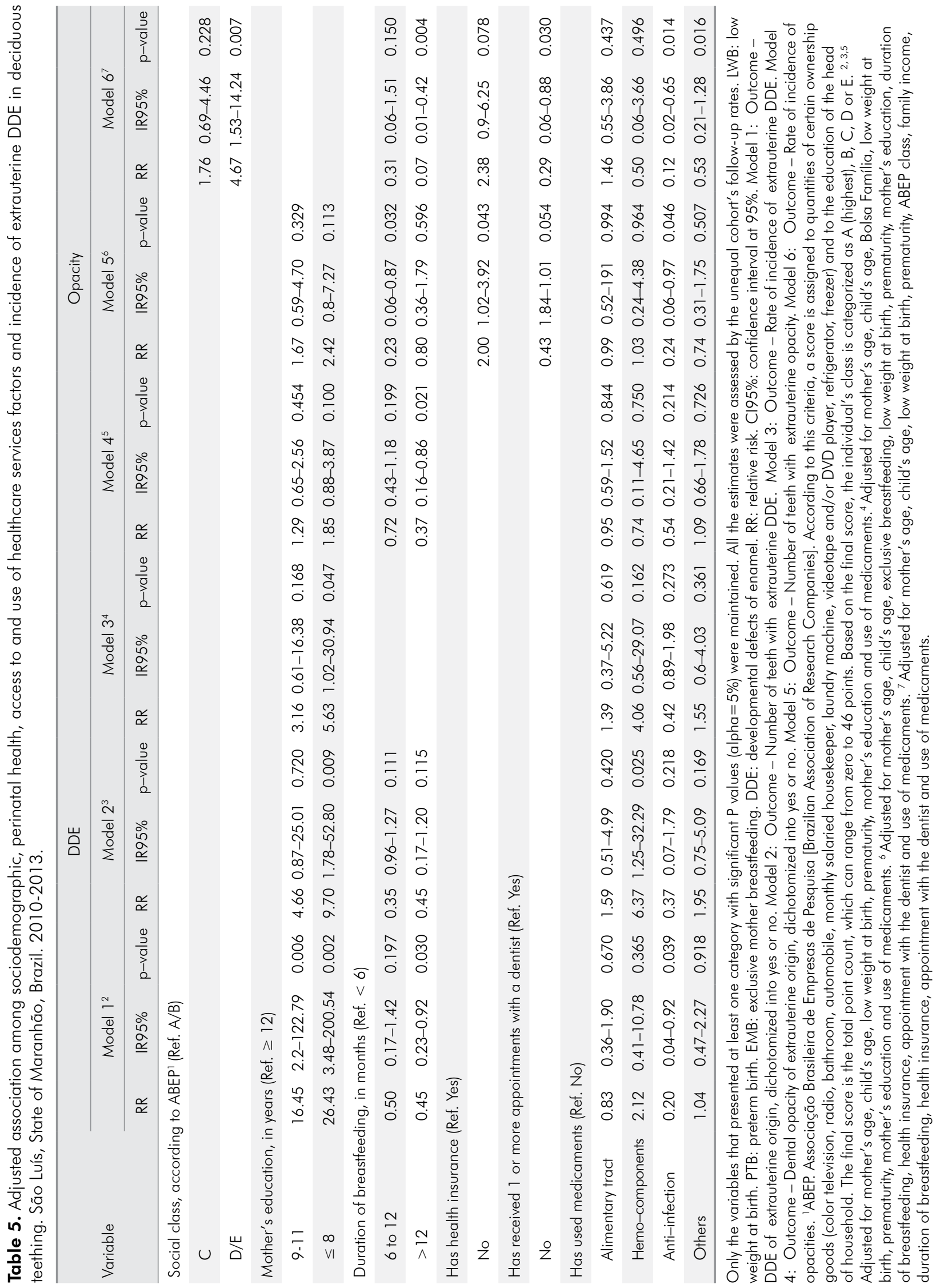


to highlight that none of the studies cited addressed the differentiation between intra- and extrauterine defects. We understand that classificate the origin of the defect is essential to identificate the risk factors that occur after the child's birth.

Although this study found no association with family income, an important finding was that having health insurance protectively influenced the number of teeth with opacities. This may be related to better means of access to health services, and, consequently, to a more effective follow-up of the child's nutritional status. ${ }^{9}$

Another interesting finding is that not having a dentist appointment showed a protective effect on the opacity incidence rate. This is a possible example of reverse causality. It is believed that making a dentist appointment in this age range is related to visible mouth problems, such as a defect of greater severity related to tooth enamel; therefore, children who present milder DDE look for a dentist more frequently. ${ }^{3}$

Yet another important finding is related to the use of medicaments. The use of anti-infection medicaments during the two weeks before the interview showed a protective effect on the presence of DDE, and on the number of teeth with opacities. Studies have pointed out that infections and high fever can be risk factors for enamel defect formation; ${ }^{6,12}$ the use of drugs can explain the outcome of this protective effect since these medicaments are used to treat infections and reduce sequelae. However, research shows that there is an association between the use of specific antibiotics to treat respiratory tract infections and DDE. ${ }^{27,28}$ Nonetheless, the studies are not conclusive as to whether the association is related to chronic infections or the use of antibiotics.

In the present investigation, the protective effect of anti-infection medicaments did not change when the models were adjusted for history of hospital admission and classification of the child's health, as related by the mother. This suggests a residual effect not explained by more severe health conditions. However, neither the severity of the disease nor the duration of medicament use was considered in this study. Seeking to avoid memory bias in recording use of the medicament, the question posed in this study referred to its use in the last two weeks; however, this is not enough time for repercussions to be manifest in tooth formation. Therefore, the act of medicating the child could reflect a profile of care and attention to the child's health by its family, rather than the protective effect of the medication itself.

A limitation of this study was the non-follow-up of the children's nutritional status using more objective parameters, in multiple episodes. However, additional analyses adjusted for the measurable weight gain of the cohort children (data not shown) have produced results similar to those already presented in the study. Controversies regarding the use of medicaments as of the first moment of life are subject to measurement bias, thereby making this issue difficult to be addressed in population studies. Alternatively, the use of vitamin and iron supplements since birth was assessed, but this variable did not present any association with the desired outcome.

One important point to be discussed is the biasing of possibilities in the diagnosis of DDE. The diagnostic criteria of enamel defects proposed by Seow ${ }^{29}$ were adopted to reduce this bias. Moreover, the likelihood of confusing DDE diagnosis with that of other defects, such as dental fluorosis, is deemed relatively low in this research, considering that the population is not exposed to systemic fluoridation. ${ }^{30}$

Despite the study limitation of not comparing the child's nutritional status from birth to the time of the current assessment-a comparison that could have an impact on the presence of DDE-the present research proposes an unprecedented methodology, by analyzing factors that have a different influence on the formation of enamel defects occurring after birth. In addition, the analysis includes the number of affected teeth. DDE incidence should be analyzed according to socioeconomic characteristics of the population studied. A further question arises regarding the possibility that the study results were generalized due to the characteristics of the population studied (Table 2).

The main strengths of this study are its prospective longitudinal design, the large sample size of its population base, with probabilistic sampling, and the assessment of the estimates for unequal probabilities of selection and follow-up losses, resulting in a reduced bias of selection of study estimates. Furthermore, the 
use of instruments validated for the classification of the outcome, and the pretest of the data collection instruments in a pilot study, was the methodological diligence used to reduce possible measurement bias. The use of a hierarchized approach by multiple Poisson regression was also taken into account, thus enabling the most appropriate adjustment for potential confusion.

Two major conclusions can be drawn. First, children living in a situation of socioeconomic vulnerability, and facing difficulties of access to healthcare services, have a higher risk of presenting extrauterine DDE, including opacities. Second, mothers who breastfeed for a period exceeding 12 months should be guarded against developing enamel defects, through protective strategies. The use of medicaments did not have any effect on the occurrence of DDE.

\section{Acknowledgments}

We would like to thank the following governmental agencies for the funding granted: Universidade Federal do Maranhão - UFMA, Fundação de Amparo a Pesquisa do Maranhão - FAPEMA, Coordenação de Aperfeiçoamento de Pessoal de Nível Superior CAPES, and Conselho Nacional de Desenvolvimento Científico e Tecnológico - CNPq.

\section{References}

1. Wong HM, Peng SM, Wen YF, King NM, McGrath CP. Risk factors of developmental defects of enamel: a prospective cohort study. PLoS One. 2014 Oct;9(10):e109351. https://doi.org/10.1371/journal.pone.0109351

2. Lunardelli SE, Peres MA. Breast-feeding and other mother-child factors associated with developmental enamel defects in the primary teeth of Brazilian children. J Dent Child (Chic). 2006 May-Aug;73(2):70-8.

3. Ribas AO, Czlusni GD. [Anomalies in dental enamel: etiology, diagnostic and treatment]. Publ. UEPG Ci. Biol. Saúde. 2004 Mar;10(1):23-36. Portuguese.

4. Takaoka LA, Goulart AL, Kopelman BI, Weiler RM. Enamel defects in the complete primary dentition of children born at term and preterm. Pediatr Dent. 2011 Mar-Apr;33(2):171-6.

5. Ferrini FR, Marba ST, Gavião MB. [Buccal problems in premature and low birth weight children]. Rev Paul Pediatr. 2007 Mar;25(1):66-71.

6. Jacobsen PE, Henriksen TB, Haubek D, Ostergaard JR. Developmental enamel defects in children prenatally exposed to anti-epileptic drugs. PLoS One. 2013;8(3):e58213. https://doi.org/10.1371/journal.pone.0058213

7. Rugg-Gunn AJ. Nutrition, diet and dental public health. Community Dent Health. 1993 Sep;10 Suppl 2:47-56.

8. Batista LR, Moreira EA, Corso AC. [Food, nutritional status and oral condition of the child]. Rev Nutr. 2007;(Mar-Apr):191-6. Portuguese. https://doi.org/10.1590/S1415-52732007000200008

9. Massoni ACdLT. Oliveira AFBd, Chaves AMB, Sampaio FC, Rosenblatt. Socioeconomic factors, nutritional risk, and enamel defects in children from João Pessoa, Paraíba State, Brazil. Cad Saude Publica. 2007 Dec;23(12):2928-37. https://doi.org/10.1590/S0102-311X2007001200014

10. Marques RF, Lopez FA, Braga JA. [Growth of exclusively breastfed infants in the first 6 months of life]. J Pediatr (Rio J). 2004 Mar;80(2):99-105.Portuguese. https://doi.org/10.2223/1147

11. Vitolo MR, Accioly E, Ramalho RA, Soares AG, Cardoso B, Erica BC. Vitamin A levels in mature milk of adolescent and adult nursing mothers from different socioeconomic strata. Rev Cienc Méd. 1999;8:3-10.

12. Salanitri S, Seow WK. Developmental enamel defects in the primary dentition: aetiology and clinical management. Aust Dent J. 2013 Jun;58(2):133-40. https://doi.org/10.1111/adj.12039

13. Pinho JRO, Lamy Filho F, Thomaz EBAF, Cruz MCFN, Libério SA. Developmental enamel defects prevalence in primary dentition acquired in intrauterine life. RBO. $2011 \mathrm{Jan} / J u l ; 68(1): 118-23$. https://doi.org/10.18363/rbo.v68n1.p.118

14. Silva AA, Batista RF, Simões VM, Thomaz EB, Ribeiro CC, Lamy Filho F, et al. Changes in perinatal health in two birth cohorts (1997/1998 and 2010) in São Luís. Maranhão State, Brazil: Cad Saud Pub. 201 July;31(7):1437-50. http://dx.doi.org/10.1590/0102-311X00100314

15. Fédération Dentaire Internationale FD. A review of the developmental defects index (DDE Index). Int Dent J. 1992 Dec;42(6):411-26.

16. Sahlstrand P, Lith A, Hakeberg M, Norén JG. Timing of mineralization of homologues permanent teeth: an evaluation of the dental maturation in panoramic radiographs. Swed Dent J. 2013;37(3):111-9.

17. Ford D, Seow WK, Kazoullis S, Holcombe T, Newman B. A controlled study of risk factors for enamel hypoplasia in the permanent dentition. Pediatr Dent. 2009 Sep-Out;3195):382-8. 
18. Chaves AM, Rosenblatt A, Oliveira OF. Enamel defects and its relation to life course events in primary dentition of Brazilian children: a longitudinal study. Community Dent Health. 2007 Mar;24(1):31-6.

19. Masumo R, Bårdsen A, Astrøm AN. Developmental defects of enamel in primary teeth and association with early life course events: a study of 6-36 month old children in Manyara, Tanzania. BMC Oral Health. 2013 May;13(1):21. https://doi.org/10.1186/1472-6831-13-21

20. Corrêa-Faria. Martins-Júnior PA, Andrade RGV, Marques LS, Ramos-Jorge ML. Perinatal factors associated with developmental defects of enamel in primary teeth: a case-control study. Braz Oral Res. 2013 Jul-Aug.;27(4):363-8. https://doi.org/10.1590/S1806-83242013005000017

21. Sabel N. Enamel of primary teeth: morphological and chemical aspects. Swed Dent J Suppl. 2012;222(222):1-77.

22. Park JC, Park JT, Son HH, Kim HJ, Jeong MJ, Lee CS, et al. The amyloid protein APin is highly expressed during enamel mineralization and maturation in rat incisors. Eur J Oral Sci. 2007 Apr;115(2):153-60. https://doi.org/10.1111/j.1600-0722.2007.00435.x

23. Associação Brasileira de Empresas de Pesquisa - ABEP. Critério de classificação econômica Brasil. 2008 [cited 2016 Mar 9]. Available from: http://www.abep.org/criterio-brasil

24. World Health Organization - WHO. Guidelines for ATC classification and DDD assignment 2014. Geneva: World Health Organization; 2013 [cited 2014 Jul 30]. Available from: http://www.whocc.no/filearchive/publications/2014_guidelines.pdf

25. Bortolozo I. EAFQ, Tiboni EB, Cândido LMB. [Milk from human milk banks for low birthweight newborns: nutritional contents and supplementation[. Rev Panam Salud Publica. 2005 Sep;16(3):199-205. Portuguese. https://doi.org/10.1590/s1020-49892004000900007

26. Lima MS, Dimenstein R, Ribeiro KD. Vitamin E concentration in human milk and associated factors: a literature review. J Pediatr (Rio J). 2014 Sep-Oct;90(5):440-8. https://doi.org/10.1016/i.jped.2014.04.006

27. Jälevik B, Norén JG, Klingberg G, Barregård L. Etiologic factors influencing the prevalence of demarcated opacities in permanent first molars in a group of Swedish children. Eur J Oral Sci. 2001 Aug;109(4):230-4. https://doi.org/10.1034/j.1600-0722.2001.00047.x

28. Hong L, Levy SM, Warren JJ, Dawson DV, Bergus GR, Wefel JS. Association of amoxicillin use during early childhood with developmental tooth enamel defects. Arch Pediatr Adolesc Med. 2005 Oct;159(10):943-8. https://doi.org/10.1001/archpedi.159.10.943

29. Seow WK. Clinical diagnosis of enamel defects: pitfalls and practical guidelines. Int Dent J. 1997 Jun; 47(3):173-82. https://doi.org/10.1002/j.1875-595X.1997.tb00783.x

30. Narvai PC, Frias AC, Fratucci MV, Antunes JL. Carnut, Frazão P. [Water fluoridation in Brazilian capitals in the beginning of the XXI century: the effectiveness in question]. Saúde Debate. 2014 July-Sep.;38(102):562-71. Portuguese. https://doi.org/10.5935/0103-1104.20140052 